\title{
Comparison of Power Plants Efficiency among 73 Countries
}

\author{
Tser-Yieth Chen, ${ }^{1}$ Tsai-Lien Yeh, ${ }^{2}$ and Yi-Ting Lee ${ }^{1}$ \\ ${ }^{1}$ Graduate Institute of International Business, National Taipei University, No. 151 University Road, Sanhsia District, \\ New Taipei City 23745, Taiwan \\ ${ }^{2}$ Department of International Business, Ming Chuan University, Section 5, No. 250, Zhong Shan North Road, Taipei 11150, Taiwan
}

Correspondence should be addressed to Tser-Yieth Chen; chenty@mail.ntpu.edu.tw

Received 22 January 2013; Revised 20 May 2013; Accepted 20 May 2013

Academic Editor: Qilian Liang

Copyright (C) 2013 Tser-Yieth Chen et al. This is an open access article distributed under the Creative Commons Attribution License, which permits unrestricted use, distribution, and reproduction in any medium, provided the original work is properly cited.

Effective and efficient production of electricity is promised to be one of the critical factors to utilize energy for sustainable development. We employ data envelopment analysis (DEA), including undesirable $\mathrm{CO}_{2}$ emissions outputs, to evaluate power plants resource utilization efficiency within 73 countries in order to incorporate the global warming effect. We find that Asia enjoys the highest technical efficiency and European countries suffer from the lowest technical efficiency among Europe, Asia, and America continents. Besides, we compare models with and without $\mathrm{CO}_{2}$ emissions and find that they have significant differences among technical and pure technical efficiencies. We also set up three hypotheses to examine gross national product (GNP), urbanization, and electricity import level factors that potentially influence power plants efficiency by Tobit regression analysis. Results show that GNP and urbanization have significant effects on power plants efficiency except electricity import level.

\section{Introduction}

This study examines the resource utilization efficiency of 73 countries' power plant electricity generation efficiency to determine whether low efficiency countries can learn from other high efficiency countries since previous studies have focused primarily on efficiency and ignored $\mathrm{CO}_{2}$ emissions. Because few studies have discussed international power plant resource utilization efficiency, we want to know and compare the power plant resource utilization efficiency of numerous nations. Data for each country's electricity generation were obtained to examine the efficiency of each country before comparing the differences between countries and to determine an approach for improving efficiency. This study includes $\mathrm{CO}_{2}$ emissions in output and uses a BCG matrix to analyze the reasons that countries have low or high efficiencies. Additionally, we consider the factors that may influence efficiency, such as GDP, GNP, continent location, urbanization, and electricity import level.

Electricity is essential to people's livelihood and is critical for every country's developmental activities [1]. Liu et al. [2] considered electricity to become indispensable to the daily life of people for a long time. The increasing demand of developing industries has resulted in the need for more electricity. Therefore, when a country experiences an electricity shortage, its people and its economy are affected.

Lam and Shiu [3] discussed the challenges confronted by power plants as more severe than those of other enterprises because energy sources have continually decreased and become more precious and international energy prices have increased. Therefore, it is essential to improve the operational performance or resource utilization efficiency of power plants [4]. A critical issue is how to provide sufficient electricity using less fuel and improve the efficiency of a power plant's operation.

Electric power has a critical function in every nation's economy. The reliability of electric power supply is one of the primary motivating factors for technical innovation and change in market organization. Electric power production is a comprehensive process that includes generation, transmission, distribution, and retailing. It involves large amounts of capital, labor, and financial resources. However, modes of power plant efficiency evaluation are lacking and are relatively less comprehensive. A power plant's efficiency is generally defined as the electricity produced per energy input. This ratio addresses only the heating value of fuels and 
neglects other variables such as installed capacity, electricity and labor used, or $\mathrm{CO}_{2}$ emissions.

Furthermore, Sueyoshi et al. [4] noted that environmental issues have recently become a critical topic. During the operation of a power plant, it generates some undesired outputs along with electricity; therefore, controlling efficiency is crucial when the same inputs are used to generate the same amount of undesirable output, such as $\mathrm{CO}_{2}, \mathrm{NO}_{2}$, and $\mathrm{SO}_{2}$.

Goto and Tsutsui [5] used data envelopment analysis (DEA) to measure overall cost efficiency and technical efficiency and to compare bilaterally between Japanese and US electric utilities. Graus et al. [6] compared the energy efficiency of fossil-fired power generation for Australia, China, France, Germany, India, Japan, Nordic countries (Denmark, Finland, Sweden, and Norway aggregated), South Korea, the United Kingdom and Ireland, and the United States; these countries generate $65 \%$ of worldwide fossil power generation. Tunç et al. [7] compared Turkey's electrical energy consumption and production with some European countries and optimization of future electrical power supply investments in Turkey.

\section{Research Methodology}

In the research methodology, three are three subsections, that is, DEA model, the selection of input and output variables, and data collection.

2.1. DEA Model. In initiating the data envelopment analysis method, Charnes et al. [8] proposed an operational framework for estimating productive efficiency (the CCR-DEA model), which demonstrated that the mechanism for calculating DEA scores can be formulated as a linear programming problem. We denote $Y_{j n}$ as the $s$ th output of the $j$ th DMU and $X_{j m}$ as the $m$ th input of the $j$ th DMU. If a DMU employs $M$ inputs to produce $N$ outputs, the score of $j$ th DMU, $H_{j}$, is a solution from the linear programming problem:

$$
\begin{aligned}
& \text { Min } \quad H_{j}=\theta-\varepsilon\left(\sum_{m=1}^{i} S_{m}{ }^{-}+\sum_{s=1}^{r} S_{s}{ }^{+}\right) \\
& \text {s.t. } \quad \sum_{n=1}^{j} \lambda_{n} X_{m n}-\theta X_{m k}+S_{m}{ }^{-}=0 \\
& \quad \sum_{n=1}^{j} \lambda_{n} Y_{s k}-S_{s}{ }^{+}=Y_{s k}, \\
& m=1,2, \ldots, i ; s=1,2, \ldots, r ; n=1,2, \ldots, j, \\
& \quad \lambda_{n} \geq 0, S_{m}{ }^{-} \geq 0, S_{s}{ }^{+} \geq 0,
\end{aligned}
$$

where $H_{j}$ is the efficiency value, $X$ denotes the input item, and $Y$ denotes the output items. $\varepsilon$ is a non-Archimedean quantity, the value of which is very minute $\left(10^{-6}\right)$.

Furthermore, we assume that $y^{g}$ and $y^{b}$ represent the good (desirable) and negative (bad or undesirable) outputs, respectively (these can also be termed "less-is-better outputs"). We wish to increase $y^{g}$ and decrease $y^{b}$ at the same time in order to improve the region's performance. In the output-based BCC envelopment model, however, both $y^{g}$ and $y^{b}$ are supposed to improve performance. To increase the good outputs and reduce the bad outputs, Seiford and Zhu [9] proceed as follows. Each undesirable output is multiplied by " -1 " and then a proper value $w$ is found to let all negative undesirable outputs be positive; that is,

$$
\bar{Y}_{j}^{b}=-Y_{j}^{b}+w>0, \quad \max \left(Y_{j}^{b}\right)+1 .
$$

Equation (1) is modified as follows:

$$
\begin{array}{ll}
\operatorname{Max} & h j \\
\text { s.t. } & \sum_{j=1}^{n} z_{j} \bar{Y}_{j}^{b} \geq h \bar{Y}_{j}^{b} \\
& \sum_{j=1}^{n} z_{j} y_{j}^{g} \geq h Y_{j}^{g} \\
& \sum_{j=1}^{n} z_{j} x_{j} \leq X_{j} \\
& \sum_{j=1}^{n} z_{j}=1, \\
Z_{j} \geq 0, \quad j=1,2, \ldots, n,
\end{array}
$$

where $h j$ is the efficiency score and $Z_{j} \geq 0$ denotes the weight of input and output.

Please note that we also calculate the pure technical efficiency and scale efficiency through the BCC model, which was proposed by Banker et al. [10] (which is the revised version of the CCR model) and can be reformulated by adding the constraint, $\sum_{n=1}^{j} \lambda_{n}=1$ to the programming problem. We can judge the DMU is a constant return to scale (CRS) when we compute $\sum_{n=1}^{j} \lambda_{n}=1$, DMU is a decreasing return to scale (DRS) when we compute $\sum_{n=1}^{j} \lambda_{n}<1$, and DMU is an increasing return to scale (IRS) when we compute $\sum_{n=1}^{j} \lambda_{n}>1$. This provides us valuable information about cost benefits. The scale efficiency score can then be derived from the overall technical efficiency and pure technical efficiency scores since the overall technical efficiency score is equal to the product of the pure technical efficiency and scale efficiency scores. Additionally, in the case of 31 regions, the efficiency of a particular region is calculated by finding the ratio of the weighted sum of outputs to the weighted sum of inputs.

2.2. The Selection of Input and Output Variables. Donthu et al. [11] emphasized the significance of variable selection because research outcomes are heavily dependent on the input and output variables used in a model. Their arguments caused studies to believe that there should be a more rigorous method than those of previous studies for selecting input and output variables for resource utilization efficiency assessment. We then employ the institution approach to choose the input and output items in the study. 
As to the inputs, there are three inputs (i.e., labor, installed capacity, and coal consumption) which are employed as follows.

Labor is also called labor force, and in this study, labor is defined as the percentage of labor used in the electric power industry. Park and Lesourd [12] showed that labor is people which are employed for the operation of a power plant. Labor input is the amount of employees in thermal power generation and is only used in the electric power industry (including transmission and distribution) [3]. Labor input is defined as the number of full-time employees plus the adjusted number of part-time employees. The adjusted number of part-time employees is calculated by (the number of part-time employees) $\times$ (wages and salaries paid for part-time employees)/(wages and salaries paid for full-time employees) [13]. The number of employees is obtained from corporate financial reports [14].

Installed capacity in this study is defined as the conventional thermal electricity's maximum amount of electricity that a station can produce at any given point in time. Campbell et al. [15] considered that installed capacity is calculated by adding a capacity reserve (for maintenance and unit failures) to the peak demand. Liu et al. [2] defined installed capacity as the maximum design load of generated electricity per month. Tunç et al. [7] stated that installed capacity is for direct heating, such as that provided for heating residences, greenhouses, and heated water.

Coal consumption is defined in this study as the amount a country consumes annually to produce electricity. Bloch et al. [16] collected coal consumption data from the Statistical Review of World Energy. Wolde-Rufael [17] believed that coal consumption is the primary source of global warming because power plants that burn coal are major contributors to rising atmospheric concentrations of the greenhouse gas carbon dioxide $\left(\mathrm{CO}_{2}\right)$. This contributes to global warming and is measured in million tons of oil equivalents.

As to the outputs, there are also three outputs (i.e., industrial electricity, residential electricity, and $\mathrm{CO}_{2}$ emissions) which are employed as follows.

As to industrial electricity, we define industrial electricity in this study as a country's entire annual industrial electricity consumption and is obtained from the Energy Information Administration (EIA). Al-Ghandoor et al. [18] considered that the industrial sector's aggregate electricity intensity, defined here as electricity consumption divided by the valueadded outputs $(\mathrm{kWh} \$ 1)$, is a key parameter for describing industrial electrical energy efficiency.

As to residential electricity, we define residential electricity in this study as a country's entire annual residential electricity consumption and it is obtained from the EIA. van Ruijven et al. [19] used the application of electricity for lighting as a proxy for household electrification rates at various income levels, assuming that electricity is the preferred energy source for lighting once electricity access is obtained. Floor space per capita is a commonly used indicator for household energy use because end-use functions such as lighting and space heating and cooling are closely related to living space [20].
In the $\mathrm{CO} 2$ emissions which is deemed as an undesirable output. We define $\mathrm{CO}_{2}$ emission as the total $\mathrm{CO}_{2}$ emissions from the consumption of coal, measured in million metric tons. Shao et al. [21] categorized energy-related consumption of $\mathrm{CO}_{2}$ emissions into coal, oil, and natural gas three types by convention. Salat [22] considered that $\mathrm{CO}_{2}$ emission is related to heating mode and inhabitant behaviors are separated from those linked to urban form and construction technology in this study.

2.3. Data Collection. Choosing suitable input and output variables is critical for obtaining a successful application of the DEA model. The DEA process is accomplished by choosing input and output variables. We synergize these variables to obtain the relative resource utilization efficiency score, and finally, use this efficiency score as a criterion to evaluate all units' relative efficiency. Therefore, how can we determine whether our input and output variables are appropriate? We introduce several methods here to consider if the input and output variables are suitable in the models. We first employ multicollinearity analysis to examine the appropriate correlation coefficient between input and input variables and then between output and output variables [23]. We then employ isotonicity diagnosis to examine the positive correlation coefficient between input and output variables [24]. We further use sensitivity analysis to increase or reduce the input or output variables sequentially to examine the efficiency variation [25]. Additionally, we test the rule of thumb issued by Golany and Roll [26]. After these steps, we collect all the required data and perform an empirical analysis.

We integrate hydro, thermal, nuclear, and renewable energy power plants into a single decision-making unit (DMU) in order to make a parallel comparison to other countries. The data used for this analysis were gathered from World Bank and the Energy Information Administration (EIA), and we use a representative sample from 2006 to 2008 of 73 countries on their input and output of their electric industry. We collected data from 2006 to 2008, to avoid the specific shocks of the world financial tsunami. Table 1 shows the mean and standard deviation of each input and output.

\section{Empirical Analysis}

In the empirical analysis, three are also three subsections, that is, variables rationale test, efficiency score calculation, and efficiency score test.

3.1. Variables Rationale Test. First, we test whether the variables are reasonable. We employ multicollinearity analysis to examine the correlation coefficient between input and input variables and then between output and output variables [27]. We used isotonicity diagnosis to examine positive correlation coefficients between input and output variables [24]. We then used sensitivity analysis to sequentially increase or reduce the input or output variables to examine variation of efficiency [25]. The obtained sensitivity analysis result does not consider the operating expenses variable because of their 
TABLE 1: Basic statistics analysis of output and inputs (DMUS $=73$ ).

(a)

\begin{tabular}{lcccc}
\hline Outputs & 2006 & 2007 & 2008 & $\begin{array}{c}\text { 2006-2008 } \\
\text { Mean }\end{array}$ \\
\hline $\begin{array}{l}\text { Industrial electricity } \\
\quad \text { Mean }\end{array}$ & 5940.0 & 6162.8 & 6467.9 & 6190.2 \\
$\quad$ SD & 19444 & 20238 & 21262 & 20314 \\
Residential electricity & & & & \\
$\quad$ Mean & 4036.8 & 4092.6 & 4371 & 4166.8 \\
$\quad$ SD & 12602 & 12742 & 14081 & 13141 \\
$\mathrm{CO}_{2}$ emission & & & & \\
$\quad \begin{array}{l}\text { Mean } \\
\text { SD }\end{array}$ & 143.41 & 149.61 & 156.45 & 149.8 \\
\hline
\end{tabular}

Source: World Bank and Energy Information Administration (EIA).

(b)

\begin{tabular}{lcccc}
\hline Inputs & 2006 & 2007 & 2008 & $\begin{array}{c}\text { 2006-2008 } \\
\text { Mean }\end{array}$ \\
\hline $\begin{array}{l}\text { Labor } \\
\quad \text { Mean }\end{array}$ & 23.2 & 23.46 & 23.24 & 33 \\
$\quad$ SD & 6.47 & 6.39 & 6.11 & 106.67 \\
Installed capacity & & & & \\
$\quad$ Mean & 32 & 33 & 34 & 17.56 \\
$\quad$ SD & 102 & 107 & 111 & 44.08 \\
Coal consumption & & & & \\
$\quad \begin{array}{l}\text { Mean } \\
\text { SD }\end{array}$ & 80363 & 84110 & 88011 & 84161 \\
\hline
\end{tabular}

Source: World Bank and Energy Information Administration (EIA).

highly correlation with other inputs. Additionally, we also test the rule of thumb issued by Golany and Roll [26].

3.2. Efficiency Score Calculation. We calculate 73 countries CCR and BCC efficiency scores and separate into three continents (Europe, America, and Asia) in Table 2. Table 2 reports the technical efficiency, pure technical efficiency, and scale efficiency scores of the 73 countries from 2006 to 2008. From Table 2, we can see that the average technical efficiency is $0.708,0.887$, and 0.811 for Europe, Asia, and America, respectively. Among three continents, Asia enjoys the highest technical efficiency (reaches 0.887 ), which implies there are $11.3 \%$ improvement in resource utilization. The technical inefficiency results from pure technical efficiency (0.753) rather than scale efficiency (0.928). That is to say, the inefficiency is from the inappropriate configuration of the input and output, rather than the inappropriate scale. Besides, the average pure technical efficiency is $0.753,0.909$, and 0.826 for Europe, Asia, and America, respectively. The average scale efficiency is $0.928,0.972$, and 0.978 for Europe, Asia, and America, respectively.

Amongst, China and India, the "Golden Brocks Countries," enjoy the efficient resource utilization efficiency. Similarly, Japan and Korea, the east-north Asia representatives, also attain the efficient performance. Even that Malaysia, Thailand, Pakistan, and Vietnam, the traditional developing east-south Asia countries, reach the efficient performance. Our result implies the highest utilization of power plants and/or a great amount of power generation in order to meet the strong power demand and economic growth in Asia.

On the contrary, European countries suffer from the lowest power plants resource utilization efficiency, irrespective the technical efficiency, pure technical efficiency, and scale efficiency. Many famous developed countries in Europe, that is, Denmark, Belgium, Ireland, Finland, Portugal, Spain, and Greece do not obtain the efficient power plants efficiency. This outcome can reasonable indicate the decreasing economic power and electricity demand. Subsequently, "European Bond Crisis" occurs and deteriorates the Europe and World economy in 2008. The PIGS (Portugal, Italy, Greece, and Spain) are technical and scale inefficiency in nature.

3.3. Efficiency Score Test. Furthermore, we separate the 73 countries into three continents and employ Kruskal-Wallis test to test the efficiency differences among the three continents (Table 3). Empirical result demonstrates that there is significant difference among three continents, in technical pure, technical efficiencies, and scale efficiency. The reason might be that the Asia enjoys higher power plant efficiency because Asia is the world manufacture center and factory. Contrarily the economic growth and power demand of Europe are decreasing gradually since twenty-one century. Besides, America has the relative stronger efficiency because it still possesses the world marketing center and well-defined infrastructure.

We further separate the 73 countries into two groups, that is, developed and developing countries, and determine whether there are differences between developed and developing countries by Mann-Whitney $U$ test. According to the results, there are significant differences in technical and pure technical efficiencies between developed and developing countries. The reason might be that the developing countries enjoy higher economic growth relative to developed countries.

Furthermore, we test the difference between model with $\mathrm{CO}_{2}$ emissions output and model without $\mathrm{CO}_{2}$ emissions, by using Mann-Whitney $U$ test. The empirical results indicate that there are significant differences in technical efficiency between model with and without $\mathrm{CO}_{2}$ emissions. Similar results can be found in pure technical efficiency and scale efficiency. The empirical results are consistent with Yeh et al. [28], demonstrating that the model with/without $\mathrm{CO}_{2}$ emissions will significantly influence the results. In the current green economic issue, the $\mathrm{CO}_{2}$ emissions output is a required output in constructed model.

\section{Hypothesis Setting and Tobit Regression Analysis}

Another important issue is the cause relationship between power plant resource utilization efficiency and its influencing factors. From the policy viewpoint, we can promote 
TABLE 2: Efficiency scores for 73 countries.

\begin{tabular}{|c|c|c|c|c|c|c|c|c|c|c|c|}
\hline \multicolumn{4}{|c|}{ Europe } & \multicolumn{4}{|c|}{ Asia } & \multicolumn{4}{|c|}{ America } \\
\hline Countries & $\mathrm{TE}$ & PTE & SE & Countries & TE & PTE & SE & Countries & TE & PTE & SE \\
\hline Albania & 0.494 & 1 & 0.494 & Armenia & 0.42 & 0.439 & 0.958 & Argentina & 1 & 1 & 1 \\
\hline Austria & 0.921 & 0.931 & 0.989 & Australia & 0.888 & 0.894 & 0.993 & Bolivia & 1 & 1 & 1 \\
\hline Belgium & 0.881 & 0.89 & 0.990 & Azerbaijan & 1 & 1 & 1 & Brazil & 1 & 1 & 1 \\
\hline Bulgaria & 0.579 & 0.59 & 0.981 & China & 1 & 1 & 1 & Colombia & 0.976 & 0.984 & 0.991 \\
\hline Croatia & 0.46 & 0.475 & 0.968 & Georgia & 1 & 1 & 1 & Costa Rica & 0.598 & 0.715 & 0.836 \\
\hline Cyprus & 0.394 & 0.517 & 0.762 & Hong Kong SAR & 0.514 & 0.539 & 0.953 & Ecuador & 0.771 & 0.771 & 1 \\
\hline Czech Republic & 0.636 & 0.647 & 0.983 & India & 1 & 1 & 1 & El Salvador & 1 & 1 & 1 \\
\hline Denmark & 0.835 & 0.85 & 0.982 & Indonesia & 1 & 1 & 1 & Guatemala & 0.424 & 0.436 & 0.972 \\
\hline Finland & 0.79 & 0.793 & 0.996 & Japan & 1 & 1 & 1 & Honduras & 0.471 & 0.53 & 0.888 \\
\hline France & 1 & 1 & 1 & Kazakhstan & 0.78 & 0.792 & 0.985 & Jamaica & 0.493 & 0.525 & 0.939 \\
\hline Germany & 1 & 1 & 1 & Korea & 1 & 1 & 1 & Netherlands & 1 & 1 & 1 \\
\hline Greece & 0.499 & 0.523 & 0.954 & Kyrgyz Republic & 0.588 & 0.667 & 0.882 & Nicaragua & 0.276 & 0.277 & 0.999 \\
\hline Hungary & 0.467 & 0.48 & 0.973 & Malaysia & 1 & 1 & 1 & Panama & 0.536 & 0.536 & 0.999 \\
\hline Ireland & 0.681 & 0.685 & 0.994 & Mongolia & 0.706 & 1 & 0.706 & Paraguay & 1 & 1 & 1 \\
\hline Italy & 0.936 & 1 & 0.936 & New Zealand & 1 & 1 & 1 & Peru & 0.873 & 0.916 & 0.953 \\
\hline Latvia & 0.195 & 0.205 & 0.951 & Pakistan & 1 & 1 & 1 & Trinidad and Tobago & 1 & 1 & 1 \\
\hline Lithuania & 0.251 & 0.274 & 0.916 & Philippines & 0.719 & 0.779 & 0.923 & United States & 1 & 1 & 1 \\
\hline Luxembourg & 0.325 & 0.551 & 0.590 & Russian Federation & 1 & 1 & 1 & Uruguay & 1 & 1 & 1 \\
\hline Macedonia & 0.511 & 0.574 & 0.890 & Sri Lanka & 0.954 & 0.968 & 0.985 & Venezuela & 1 & 1 & 1 \\
\hline Malta & 1 & 1 & 1 & Tajikistan & 1 & 1 & 1 & & & & \\
\hline Moldova & 0.178 & 0.289 & 0.616 & Thailand & 1 & 1 & 1 & & & & \\
\hline Norway & 1 & 1 & 1 & Turkey & 0.822 & 0.844 & 0.974 & & & & \\
\hline Poland & 1 & 1 & 1 & Vietnam & 1 & 1 & 1 & & & & \\
\hline Portugal & 0.798 & 0.818 & 0.976 & & & & & & & & \\
\hline Romania & 0.525 & 0.528 & 0.994 & & & & & & & & \\
\hline Slovak Republic & 0.86 & 0.911 & 0.944 & & & & & & & & \\
\hline Spain & 0.751 & 0.827 & 0.908 & & & & & & & & \\
\hline Sweden & 0.97 & 0.991 & 0.979 & & & & & & & & \\
\hline Switzerland & 1 & 1 & 1 & & & & & & & & \\
\hline Ukraine & 1 & 1 & 1 & & & & & & & & \\
\hline United Kingdom & 1 & 1 & 1 & & & & & & & & \\
\hline Average & 0.708 & 0.753 & 0.928 & & & 0.887 & 0.909 & 0.972 & 0.811 & 0.826 & 0.978 \\
\hline Standard deviation & 0.273 & 0.254 & 0.131 & & & 0.179 & 0.162 & 0.065 & 0.254 & 0.243 & 0.045 \\
\hline
\end{tabular}

TE: technical efficiency; PTE: pure technical efficiency; SE: scale efficiency.

power plant resource utilization efficiency via creating sound environment settings. Thus we propose three environment settings, that is, GNP, urban population, and electricity import level.

Sözen and Arcaklioglu [29] have shown that GNP can be used to predicate the current and future levels of energy consumption. Higher GNP is indicative of greater energy demand; thus, a country should improve its electricity efficiency to meet the increased demand. Countries with higher GNP can employ higher technology innovation and R\&D effort in energy saving and energy efficiency improvement process. We then assume that GNP positively influences a country's energy production efficiency. Note that high gross domestic product (GDP) growth rates of Crete almost doubled the gross national product (GNP) growth average. These growth rates tend to adapt to national rates. Therefore, we use GNP instead of GDP. Thus, we propose $H 1$.

H1: GNP Can Positively Influence a Country's Energy Production Efficiency. Rapid growth in population will lead to urbanization, which will further cause more usage of energy. Shahbaz and Lean [30] used urban population as share of total population as the proxy for urbanization. The rise in economic activities caused by urbanization increases the demand for energy consumption. Bodach and Hamhaber [31] indicated that energy consumption is caused by urbanization 
TABLE 3: Results of Kruskal-Wallis and Mann-Whitney $U$ test of different scenarios.

\begin{tabular}{|c|c|c|c|c|}
\hline Scenarios & Statistics & TE & PTE & SE \\
\hline \multirow{3}{*}{$\begin{array}{l}\text { Europe, America, and } \\
\text { Asia }\end{array}$} & Chi square & 14.629 & 12.585 & 14.093 \\
\hline & $\begin{array}{l}\text { Degrees of } \\
\text { freedom }\end{array}$ & 2 & 2 & 2 \\
\hline & $P$ value & $0.002^{* *}$ & $0.006^{* *}$ & $0.003^{* *}$ \\
\hline \multirow{2}{*}{$\begin{array}{l}\text { Developed and } \\
\text { developing countries }\end{array}$} & $Z$-value & -1.882 & -2.285 & -0.355 \\
\hline & $P$ value & $0.06^{*}$ & $0.022^{* *}$ & 0.723 \\
\hline \multirow{2}{*}{$\begin{array}{l}\text { With and without } \\
\mathrm{CO}_{2} \text { emission }\end{array}$} & $Z$-value & -8.271 & -7.735 & -2.5 \\
\hline & $P$ value & $0.000^{* *}$ & $0.000^{* *}$ & $0.012^{* *}$ \\
\hline
\end{tabular}

TE: technical efficiency; PTE: pure technical efficiency; SE: scale efficiency.

${ }^{* *}$ Represents significant at 0.05 level and ${ }^{*}$ represents significant at 0.10 level.

in the short run. Chen [32] and Bodach and Hamhaber [31] concluded that the relationship between urbanization and energy consumption is positive and highly significant. According to these studies, we propose whether urbanization can positively influence a country's energy production efficiency. Thus, we propose $\mathrm{H} 2$.

H2: Urban Population Can Positively Influence Energy Production Efficiency. When a country with a higher energy endowment, the less electricity efficiency the country has; resulting from lower opportunity cost. Alternatively, when a country is with a scarce nature energy sources and needs to import energy, the country must produce electricity more efficiently, since they afford extra energy purchase cost from another country. Kim et al. [33] focused on the rising dependence of the economy on energy imports and indicated that a country must reduce its dependence on energy imports to improve energy efficiency. Balachandra et al. [34] addressed that the rising energy prices and imports have influence on energy conservation and efficiency measures. According to the discussed study, we assume that high electricity imports imply low-efficiency energy production. Thus, we propose H3.

H3: Electricity Import Level Can Negatively Influence Power Plant Efficiency. We then employ the Tobit regression model to determine whether the efficiency scores are causally related to three environmental characteristics such as GNP level, the urbanization population, and the level of imported electricity (Table 3). The function of a regression model can be expressed as $Y=a+b X$, where $Y$ represents the dependent variable and $X$ represents the regression form to a logistic probability function because the efficiency ranges from zero to one. The transformed regression function is expressed as $\ln (Y /(1-$ $Y))=a+b X$, derived from $Y=F(a+b X)=1 /(1+\exp (-a-$ $b x)$ ).

The Tobit regression analysis result shows that GNP and urban population have high positive significance with power plants efficiency except the level of imported electricity.

The Tobit regression result shows that GNP can positively influence a country's power plant efficiency $(t=5.66$; $P=0.000$ ) and the $H 1$ is accepted (Table 4). Our result is consistent with the position of Sözen and Arcaklioglu [29],
TABLE 4: Results of the Tobit regression analysis.

\begin{tabular}{lcccc}
\hline Parameter & Coefficient & $t$-value & $P$ value & Hypothesis \\
\hline GNP & $1.66 E-13$ & $5.66^{* *}$ & $0.000^{* *}$ & Not rejected \\
Urban & 0.00484 & $3.88^{* *}$ & $0.000^{* *}$ & Not rejected \\
Import & 0.00096 & 0.36 & 0.72 & Rejected \\
\hline
\end{tabular}

indicating that countries with a higher GNP are more efficient at power generation in order to meet the higher electricity demand. Furthermore, urban population can positively influence power plant efficiency $(t=3.88 ; P=0.000)$ and the $H 2$ is hold since the countries with higher urbanized standards are resulting in more energy consumption [31, 32]. Power plant managers can adopt more efficient forms to generate electricity due to the pressure in higher population density, scarcity of land supply. Besides, the feasibility and accessibility of power plant generation technique can stimulate the improvement and upgrade in power plant efficiency.

However, the electricity import level has no influence on power plant efficiency $(t=0.36 ; P=0.720)$ and the $\mathrm{H} 3$ is rejected, indicating that the power plant efficiency has no influence on the countries with or without rich energy endowment. Military strategy and political consideration might be more important factors than the economic opportunity cost consideration.

\section{Conclusion}

The majority of previous studies had only focused primarily on analyzing electricity as an output. Few studies had included undesirable output- $\mathrm{CO}_{2}$ emissions in their model. In this study, we included $\mathrm{CO}_{2}$ emissions in our data envelopment analysis model to estimate the power plants resource utilization efficiency and to compare the difference between model with $\mathrm{CO}_{2}$ and without $\mathrm{CO}_{2}$ emissions. Our conclusion showed that the models with and without $\mathrm{CO}_{2}$ emissions have significant differences among technical and pure technical efficiencies, indicating that undesirable output- $\mathrm{CO}_{2}$ emissions are a critical environment factor in the model. It had become a global consensus that $\mathrm{CO}_{2}$ emissions cause climate warming [21]. When analyzing energy production efficiency, we cannot focus only on the amount of energy that was produced; $\mathrm{CO}_{2}$ emissions also require consideration. Besides, the DEA in this study provided detailed demonstration that there was a significant difference in power plants resource utilization efficiency among different continents as well as different stages of economic development.

As to the efficiency differences among Europe, Asia, and America continents, Asia enjoys the highest technical efficiency among the three continents. On the contrary, European countries suffer from the lowest technical efficiency. Empirical results demonstrated the highest utilization of power plants and/or a great amount of power generation is needed in order to meet the strong power demand and economic growth in Asia. On the contrary, the decreasing economic power and electricity demand in Europe resulted in the lower power plant efficiency.

We further employed Tobit regression analysis to identify critical factors that might influence electricity production 
efficiency. We examined GNP, urban population, and electricity import level, and the empirical results suggested that GNP and urban population have significantly influenced electricity production efficiency. Besides, electricity import level has not significantly influenced electricity efficiency, indicating that military strategy and political consideration might be more important factors than the economic opportunity cost consideration.

\section{References}

[1] A. Vaninsky, "Efficiency of electric power generation in the United States: analysis and forecast based on data envelopment analysis," Energy Economics, vol. 28, no. 3, pp. 326-338, 2006.

[2] C. H. Liu, S. J. Lin, and C. Lewis, "Evaluation of thermal power plant operational performance in Taiwan by data envelopment analysis," Energy Policy, vol. 38, no. 2, pp. 1049-1058, 2010.

[3] P.-L. Lam and A. Shiu, "Efficiency and productivity of China's thermal power generation," Review of Industrial Organization, vol. 24, no. 1, pp. 73-93, 2004.

[4] T. Sueyoshi, M. Goto, and T. Ueno, "Performance analysis of US coal-fired power plants by measuring three DEA efficiencies," Energy Policy, vol. 38, no. 4, pp. 1675-1688, 2010.

[5] M. Goto and M. Tsutsui, "Comparison of productive and cost efficiencies among Japanese and US electric utilities," Omega, vol. 26, no. 2, pp. 177-194, 1998.

[6] W. H. J. Graus, M. Voogt, and E. Worrell, "International comparison of energy efficiency of fossil power generation," Energy Policy, vol. 35, no. 7, pp. 3936-3951, 2007.

[7] M. Tunç, Ü. Çamdali, and C. Parmaksizoglu, "Comparison of Turkey's electrical energy consumption and production with some European countries and optimization of future electrical power supply investments in Turkey," Energy Policy, vol. 34, no. 1, pp. 50-59, 2006.

[8] A. C. Charnes, W. W. Cooper, and E. Rhodes, "Measuring the efficiency of decision making units," European Journal of Operational Research, vol. 2, no. 6, pp. 429-444, 1978.

[9] L. M. Seiford and J. Zhu, "Modeling undesirable factors in efficiency evaluation," European Journal of Operational Research, vol. 142, no. 1, pp. 16-20, 2002.

[10] R. D. Banker, A. Charnes, and W. W. Cooper, "Models for estimation of technical and scale inefficiencies in data envelopment analysis," Management Science, vol. 30, no. 9, pp. 1078-1092, 1984.

[11] N. Donthu, E. K. Hershberger, and T. Osmonbekov, "Benchmarking marketing productivity using data envelopment analysis," Journal of Business Research, vol. 58, no. 11, pp. 1474-1482, 2005.

[12] S.-U. Park and J.-B. Lesourd, "The efficiency of conventional fuel power plants in South Korea: a comparison of parametric and non-parametric approaches," International Journal of Production Economics, vol. 63, no. 1, pp. 59-67, 2000.

[13] J. Nemoto and M. Goto, "Measurement of dynamic efficiency in production: an application of data envelopment analysis to Japanese electric utilities," Journal of Productivity Analysis, vol. 19, no. 2-3, pp. 191-210, 2003.

[14] M. Nakano and S. Managi, "Regulatory reforms and productivity: an empirical analysis of the Japanese electricity industry," Energy Policy, vol. 36, no. 1, pp. 201-209, 2008.
[15] H. Campbell, G. Montero, C. Pérez, and A. Lambert, "Efficient energy utilization and environmental issues applied to power planning," Energy Policy, vol. 39, no. 6, pp. 3630-3637, 2011.

[16] H. Bloch, S. Rafiq, and R. Salim, "Coal consumption, $\mathrm{CO}_{2}$ emission and economic growth in China: empirical evidence and policy responses," Energy Economics, vol. 34, no. 2, pp. 518528, 2012.

[17] Y. Wolde-Rufael, "Coal consumption and economic growth revisited," Applied Energy, vol. 87, no. 1, pp. 160-167, 2010.

[18] A. Al-Ghandoor, J. O. Jaber, M. Samhouri, and I. Al-Hinti, "Analysis of aggregate electricity intensity change of the Jordanian industrial sector using decomposition technique," International Journal of Energy Research, vol. 33, no. 3, pp. 255-266, 2009.

[19] B. J. van Ruijven, D. P. van Vuuren, B. J. M. de Vries et al., "Model projections for household energy use in India," Energy Policy, vol. 39, no. 12, pp. 7747-7761, 2011.

[20] C. P. Barros and N. Peypoch, "Technical efficiency of thermoelectric power plants," Energy Economics, vol. 30, no. 6, pp. 3118$3127,2008$.

[21] S. Shao, L. L. Yang, M. B. Yu, and M. L. Yu, "Estimation, characteristics, and determinants of energy-related industrial $\mathrm{CO}_{2}$ emissions in Shanghai (China), 1994-2009," Energy Policy, vol. 39, no. 10, pp. 6476-6494, 2011.

[22] S. Salat, "Energy loads, $\mathrm{CO}_{2}$ emissions and building stocks: morphologies, typologies, energy systems and behaviour," Building Research \& Information, vol. 37, no. 5-6, pp. 598-609, 2009.

[23] A. Charnes, W. W. Cooper, A. Y. Lewin, R. C. Morey, and J. Rousseau, "Sensitivity and stability analysis in dea," Annals of Operations Research, vol. 2, no. 1, pp. 139-156, 1984.

[24] W. F. Bowlin, "Evaluating the efficiency of U.S. air force realproperty maintenance activities," Journal of the Operational Research Society, vol. 38, no. 2, pp. 127-135, 1987.

[25] N. Donthu and B. Yoo, "Retail productivity assessment using data envelopment analysis," Journal of Retailing, vol. 74, no. 1, pp. 89-105, 1998.

[26] B. Golany and Y. Roll, "An application procedure for DEA," Omega, vol. 17, no. 3, pp. 237-250, 1989.

[27] A. Charnes, W. W. Cooper, B. Golany, L. Seiford, and J. Stutz, "Foundations of data envelopment analysis for ParetoKoopmans efficient empirical production functions," Journal of Econometrics, vol. 30, no. 1-2, pp. 91-107, 1985.

[28] T.-L. Yeh, T.-Y. Chen, and P.-Y. Lai, "A comparative study of energy utilization efficiency between Taiwan and China," Energy Policy, vol. 38, no. 5, pp. 2386-2394, 2010.

[29] A. Sözen and E. Arcaklioglu, "Prediction of net energy consumption based on economic indicators (GNP and GDP) in Turkey," Energy Policy, vol. 35, no. 10, pp. 4981-4992, 2007.

[30] M. Shahbaz and H. H. Lean, "Does financial development increase energy consumption? The role of industrialization and urbanization in Tunisia," Energy Policy, vol. 40, no. 1, pp. 473479, 2012.

[31] S. Bodach and J. Hamhaber, "Energy efficiency in social housing: opportunities and barriers from a case study in Brazil," Energy Policy, vol. 38, no. 12, pp. 7898-7910, 2010.

[32] J. J. Chen, "Comparison of energy efficiency of developed regions in china at similar economic level between 1995 and 2007," Journal of Sustainable Development, vol. 3, no. 4, pp. 625638, 2010. 
[33] H. Kim, E.-S. Shin, and W.-J. Chung, "Energy demand and supply, energy policies, and energy security in the Republic of Korea," Energy Policy, vol. 39, no. 11, pp. 6882-6897, 2011.

[34] P. Balachandra, D. Ravindranath, and N. H. Ravindranath, "Energy efficiency in India: assessing the policy regimes and their impacts," Energy Policy, vol. 38, no. 11, pp. 6428-6438, 2010. 


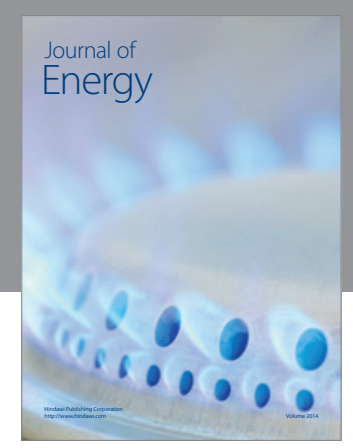

Journal of

Industrial Engineering
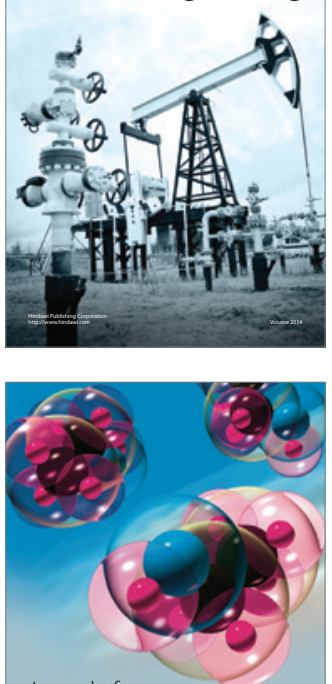

Fuels
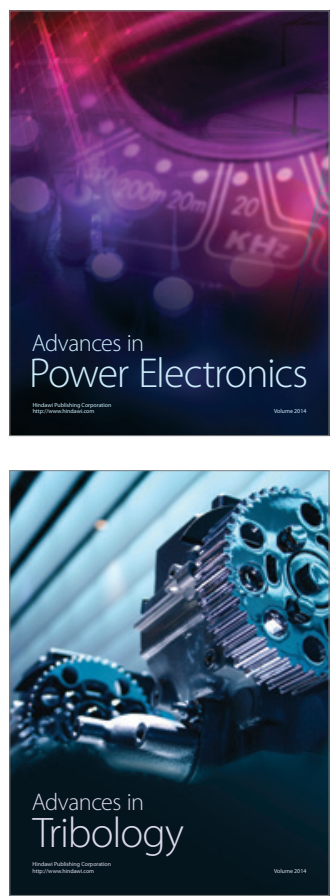

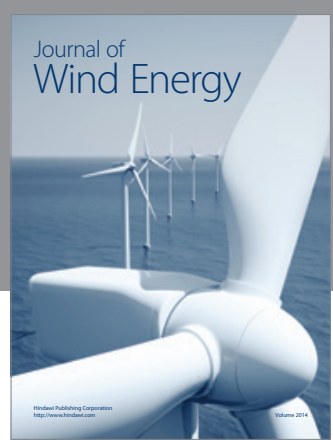

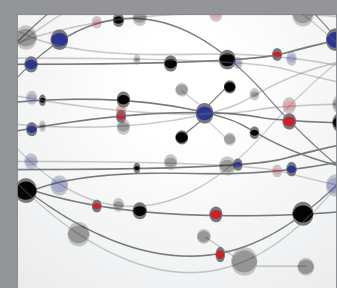

The Scientific World Journal

Submit your manuscripts at http://www.hindawi.com

Journal of

Structures
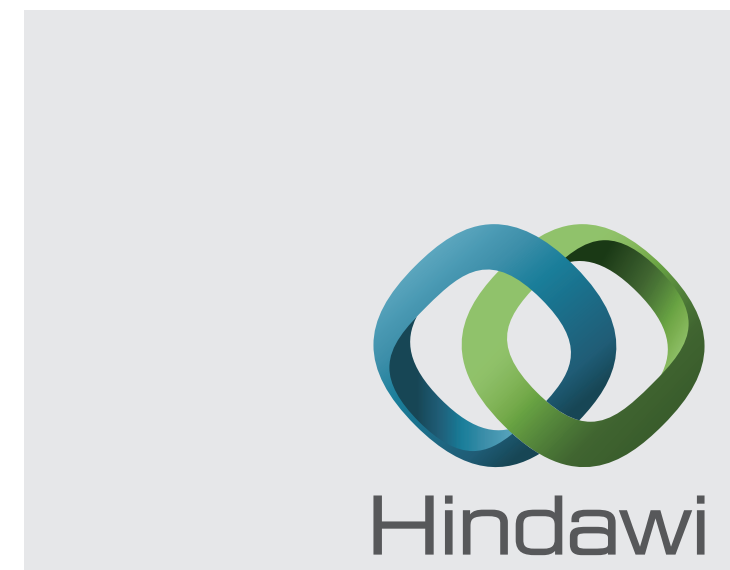

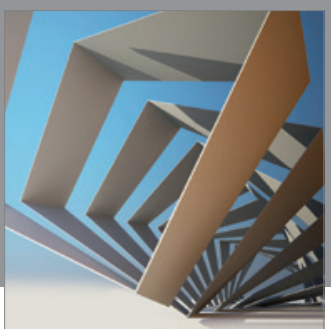

Rotating

Machinery
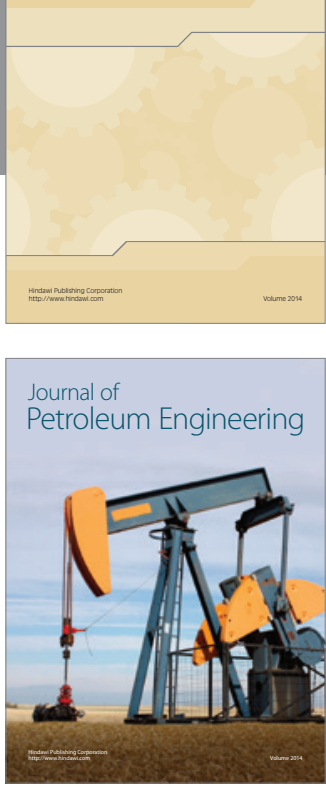

Journal of

Solar Energy
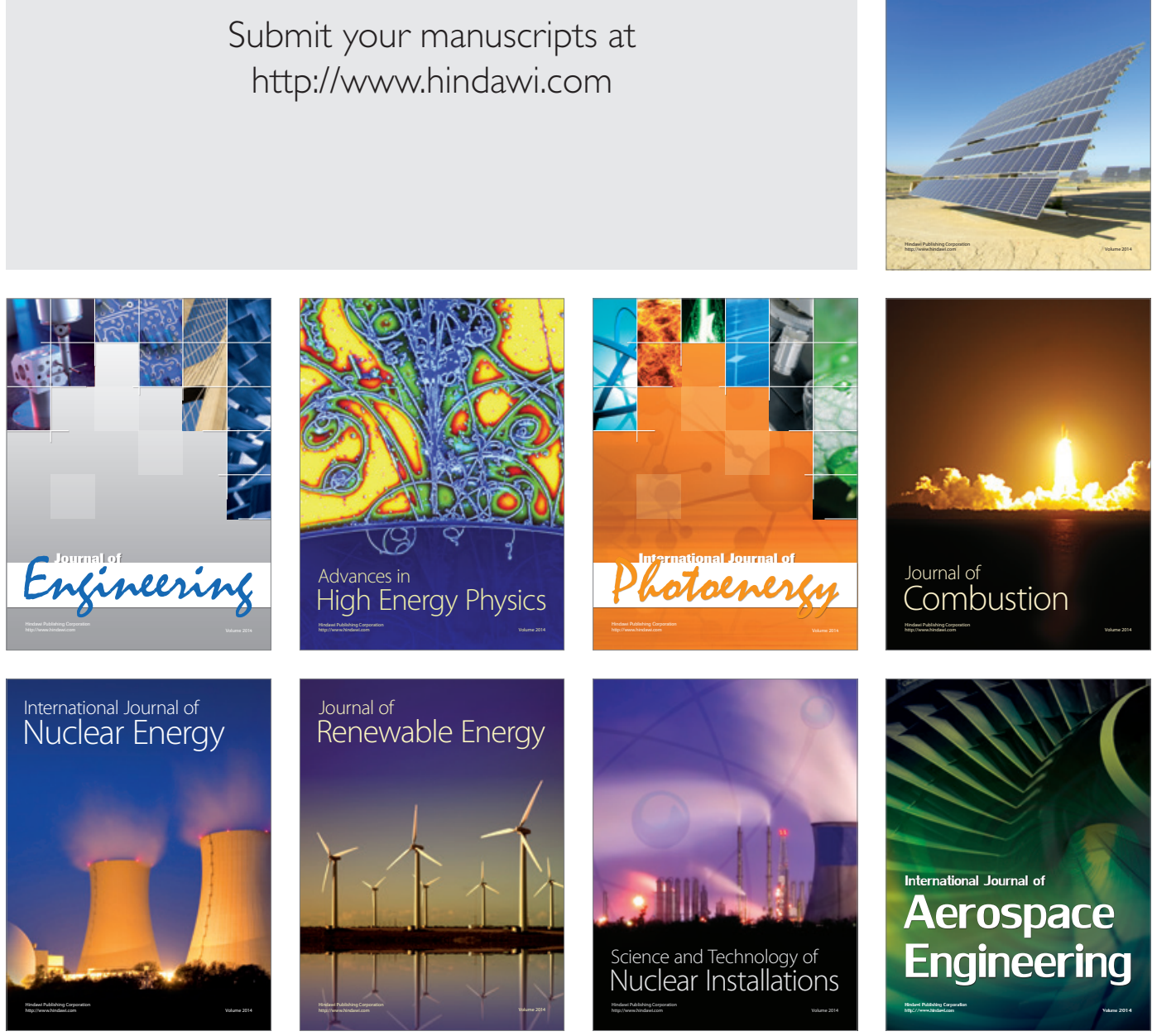